\title{
Effect of Cement Type and Water Storage Time on the Push-Out Bond Strength of a Glass Fiber Post
}

\author{
Kátia Rodrigues REIS ${ }^{1}$ \\ George Miguel SPYRIDES ${ }^{1}$ \\ Jonas Alves de OLIVEIRA ${ }^{2}$ \\ Alexandre Abrão JNOUB ${ }^{3}$ \\ Kátia Regina Hostilio Cervantes DIAS ${ }^{4}$ \\ Gerson BONFANTE 5
}

\begin{abstract}
${ }^{1}$ Department of Prosthodontics, Dental School, UFRJ - Federal University of Rio de Janeiro, Rio de Janeiro, RJ, Brazil ${ }^{2}$ Department of Prosthodontics, UEA - Amazonas State University, Manaus, AM, Brazil

${ }^{3}$ Department of Prosthodontics, UVA - Veiga de Almeida University, Rio de Janeiro, RJ, Brazil

${ }^{4}$ Department of Dental Clinics, Dental School, UFRJ - Federal University of Rio de Janeiro, Rio de Janeiro, RJ, Brazil

${ }^{5}$ Department of Prosthodontics, Bauru Dental School, USP - University of São Paulo, Bauru, SP, Brazil
\end{abstract}

\begin{abstract}
This study investigated the effects of the cement type and the water storage time on the push-out bond strength of a glass fiber post. Glass fiber posts (Fibrekor, Jeneric Pentron) were luted to post spaces using a self-cured resin cement (C\&B Cement [CB]), a glass ionomer cement (Ketac Cem [KC]) or a resin-modified glass ionomer cement (GC FujiCEM [FC]) according to the manufacturers' instructions. For each luting agent, the specimens were exposed to one of the following water storage times ( $\mathrm{n}=5)$ : 1 day (T1), 7 days (T7), 90 days (T90) and 180 days (T180). Push-out tests were performed after the storage times. Control specimens were not exposed to water storage, but subjected to the push-out test $10 \mathrm{~min}$ after post cementation. Data (in MPa) were analyzed by Kruskal-Wallis and Dunn's test $(\alpha=0.05)$. Cement type and water storage time had a significant effect $(\mathrm{p}<0.05)$ on the push-out bond strength. CB showed significantly higher values of retention $(\mathrm{p}<0.05)$ than $\mathrm{KC}$ and $\mathrm{FC}$, irrespective of the water storage time. Water storage increased significantly the push-out bond strength in T7 and T90, regardless of the cement type $(p<0.05)$. The results showed that fiber posts luted to post spaces with the self-cured resin cement exhibited the best bonding performance throughout the 180-day water storage period. All cements exhibited a tendency to increase the bond strength after 7 and 90 days of water storage, decreasing thereafter.
\end{abstract}

Key Words: fiber post, resin cement, glass ionomer cement, hygroscopic expansion.

\section{INTRODUCTION}

Since its introduction in the early 1990 s, glass fiber-reinforced composite posts have gained popularity for the restoration of endodontically treated teeth. These posts present a modulus of elasticity similar to that of the dentin and can absorb forces concentrated along the root, decreasing the probability of root fractures (1). Conversely, adhesive failures usually occur through fiber posts debonding inside root canals (2).

Fiber posts are usually luted to root canals using dual-cured resin cements. Ideally, the adhesive cementation within the root canal should create a gap free post-cement-dentin interface. This monoblock concept was initially proposed as the retention mechanism of fiber posts. Although recent scientific evidence suggests that this hypothesis is real (3), others studies using scanning electron microscopy (4) or confocal microscopy (5) have consistently showed the presence of structural discontinuities in the adhesive interface, such as gaps or cracks.

Bonding to intraradicular dentin is challenged by the long narrow root-canal geometric shape, which is highly unfavorable to relieve the polymerization shrinkage stress of resin-based cements. The high C-factor may disrupt the bonding sealing and form gaps, particularly at the cement-dentin interface. In fact, the

Correspodence: Profa. Dra. Kátia Rodrigues Reis, Universidade Federal do Rio de Janeiro, Faculdade de Odontologia, Departamento de Prótese Dentária, Rua Prof. Rodolpho Paulo Rocco 325, $2^{\circ}$ andar, Ilha da Cidade Universitária, 21941-590 Rio de Janeiro, RJ, Brasil. Tel: +55-21-2562-2029. Fax: +55-21-2562-2028. e-mail: katiarreis@yahoo.com.br 
effective retention mechanism for fiber posts to the root canals is largely derived from sliding friction of the cement against the internal walls of root canals instead of true adhesion to intraradicular dentin (6).

Self-cured resin cements (6) or water-based cements, such as glass ionomer cements (GICs) $(7,8)$, have been suggested as alternatives for the luting of fiber posts. Because of the slower setting reaction, self-cured resin cements are more likely to relieve the shrinkage stresses via resin flow through the canals orifices or dentinal tubules (7). Moreover, the viscoelastic properties of GICs and resin-modified GICs (RMGICs) render them more favorable to the preservation of bond integrity than the stiffer resin based-cements during the polymerization shrinkage (8). The postmaturation hygroscopic expansion of these cements offsets their initial setting shrinkage, and may result a more intimate adaptation between cement and dentin (9).

Thus, a post retention strategy that relies on increasing the frictional resistance to post dislodgment via delayed hygroscopic expansion of the cements can play an important role in the retention mechanism of fiber posts. Such a strategy may be obtained by the diffusion of the residual water present within tooth tubules of endodontically treated teeth towards the cement layer. The presence of residual water in root dentin was recently confirmed by a study that evaluated the use of simplified adhesives in endodontically treated tooth, which showed evident water transudation from the root dentin through permeable adhesives (10). This result suggests that the residual water present inside the dentinal tubules is not completely eliminated by drying the root canal with paper points only. Therefore, this residual water within the dentinal tubules could be advantageously employed to achieve postmaturation hygroscopic expansion of GICs and RMGICs that are employed for luting fiber posts.

It was hypothesized that water from the root dentin may slowly permeate through the cement layer and improve the push-out bond strength of the cements used for luting fiber posts. However, the long-term effect of water permeation at the cement-dentin interface of glass fiber posts is not yet known. The objective of this study was to evaluate the push-out bond strength of luted glass fiber posts after specimen storage in an aqueous medium that permitted water sorption over time. The null hypothesis tested was that cement type and water storage time do not affect the push-out bond strength of fiber posts.

\section{MATERIAL AND METHODS}

\section{Specimen Preparation}

Seventy-five extracted single-rooted, human teeth were collected after the patients' informed consent had been obtained under a protocol reviewed and approved by the Ethics Committee of the Bauru Dental School, University of São Paulo, Brazil (Protocol \# 85/2006). The teeth were stored in $1 \%$ chloramine $\mathrm{T}$ at $4^{\circ} \mathrm{C}$ until use. The crown portion of each tooth was removed at $1 \mathrm{~mm}$ above the cementoenamel junction, using a low-speed diamond saw (Isomet; Buehler Ltd., Lake Bluff, IL, USA) under copious water cooling. Cleaning and shaping was performed with a step-back technique using stainless steel endodontic files (Dentsply Maillefer, Ballaigues, Switzerland) to ISO size 35 and 0.06 taper and 5\% sodium hypochlorite as irrigant. The canals were filled with gutta-percha and a resin sealer (AH Plus, Dentsply International Inc., Petropólis, RJ, Brazil) using the lateral condensation technique. The filled roots were stored for $24 \mathrm{~h}$ in physiological saline at $37^{\circ} \mathrm{C}$ before removing the coronal gutta-percha with the preshaping drill from the Fibrekor glass fiber posts system (Fibrekor post; Jeneric Pentron Incorporated, Wallingford, CT, USA), leaving a 4-mm-long apical seal. The post space was prepared at 9-mm depth using the low-speed drill from the Fibrekor post system to match the size of the selected post (\#3).

Each root was randomly assigned into one of three groups according to the luting agent employed for post cementation. The classification and composition of these luting agents are depicted in Table 1. Table 2 summarizes the handling of these cements and the dentin pretreatment, where applicable, that was performed in accordance with the manufacturers' instructions. Each group was further subdivided in five subgroups $(\mathrm{n}=5)$ according to the water storage time: 1 day (T1), 7 days (T7), 90 days (T90) and 180 days (T180). Control specimens were not exposed to water storage, but subjected to the push-out test $10 \mathrm{~min}$ after post cementation. Each post was cleaned with alcohol, dried with air blowing and luted to the post space.

For each group, a secondary coronal seal of the exposed dentin along the coronal portion of the root was created immediately with the self-etch adhesive (Tyrian Spe, Bisco Inc., Schaumburg IL, USA). Afterwards, a core build up was made around the fiber post using the Bis-Core composite (Bisco Inc.). The specimens were stored in deionized water at $37^{\circ} \mathrm{C}$ from 1 to 180 days, 
except for the control specimens. The portion of each root containing the fiber post was sectioned in five to six 1-mm thick slices with the diamond saw (Isomet; Buehler Ltd.) under copious water cooling.

\section{Bond Strength Test (Thin Slice Push-Out Test)}

Each post was carried by a cylindrical plunger (1.5 mm diameter) connected to a universal testing device (Emic DL-1000; Equipamentos e Sistemas de Ensaio Ltda, São José dos Pinhais, PR, Brazil). The load was applied on the apical aspect of the root slice in an apicalcoronal direction, resulting in shear stresses along the luted interface. The load was applied at a speed of 0.5 $\mathrm{mm} / \mathrm{min}$ until failure characterized by the extrusion of the post segment from the root slice.

In order to express the push-out bond strength in MPa, the load at the time of failure expressed in $\mathrm{N}$ was divided by the interfacial area of the post fragment. This refers to the lateral surface of a cylinder, which is calculated using the following equation: $S=2 \pi \mathrm{r} x \mathrm{~h}$, where $\pi$ is the constant $3.14, \mathrm{r}$ is the post radius and $\mathrm{h}$ is the slice thickness in $\mathrm{mm}$.

\section{Statistical Analysis}

Each root was treated as a statistical unit. Data from the root slices were pooled to give a single mean and standard deviation for each root. The push-out bond strength data were analyzed for normality of distribution (Kolmogorov-Smirnov test) and homogeneity of variances among groups (Levene's test). KruskalWallis test and post hoc analysis with Dunn's test were performed to assess the effect of cement type and water storage time on push-out bond strength. All analyses were conducted at the level of significance of 0.05 .

\section{RESULTS}

Table 3 shows the push-out bond strengths of the three cements subjected or not to water storage. Cement type and water storage time influenced significantly the

Table 1. Classification, chemical composition and batch numbers of tested cements.

\begin{tabular}{|c|c|c|c|}
\hline Material & Manufacturer & Type & Chemical composition \\
\hline $\begin{array}{l}\text { C\&B }{ }^{\mathrm{TM}} \text { Cement }[\mathrm{CB}] \\
(\text { Batch No. 0600005072) }\end{array}$ & $\begin{array}{l}\text { Bisco, Schaumburg, } \\
\text { IL, USA }\end{array}$ & $\begin{array}{l}\text { Resin cement, } \\
\text { self-cured }\end{array}$ & $\begin{array}{l}\text { Silica, Bis-GMA, E2BADMA, TEGDMA, } \\
\text { glass, sodium fluoride. }\end{array}$ \\
\hline $\begin{array}{l}\text { Ketac Cem [KC] } \\
\text { (Batch No.82229) }\end{array}$ & $\begin{array}{l}\text { 3M ESPE, St. Paul, } \\
\text { MN, USA }\end{array}$ & $\begin{array}{l}\text { Glass ionomer } \\
\text { cement, self-cured }\end{array}$ & $\begin{array}{l}\text { Powder: glass powder, pigments, polycarboxylic acid } \\
\text { Liquid: tartaric acid, water, conservation agents }\end{array}$ \\
\hline $\begin{array}{l}\text { GC FujiCEM [FC] } \\
\text { (Batch No. 0508101) }\end{array}$ & $\begin{array}{l}\text { GC Corp., Tokyo, } \\
\text { Japan }\end{array}$ & $\begin{array}{l}\text { Resin-modified } \\
\text { glass ionomer } \\
\text { cement, self-cured }\end{array}$ & $\begin{array}{l}\text { Paste A: fluoroaluminosilicate glass, HEMA, } \\
\text { dimethacrylate, pigment, initiator } \\
\text { Paste B: Polyacrylic acid, distilled water, } \\
\text { silica powder, initiator }\end{array}$ \\
\hline
\end{tabular}

Bis-GMA = bisphenol-A diglycidyl ether dimethacrylate; E2BADMA = ethoxylated bisphenol-A diglycidyl ether dimethacrylate; TEGDMA = triethylene glycol dimethacrylate; HEMA = 2-hydroxyethyl methacrylate.

Table 2. Step-by-step handling of the tested cements.

\begin{tabular}{ccc}
\hline C\&B Cement & Ketac Cem & FujiCEM \\
\hline - Apply Uni-etch 32\% (Batch No. 0600005026) to dentin for 15 & & - Apply GC Dentin \\
s, rinse and gently air-dry & - Mix 1 measuring & Conditioner to dentin for 20 \\
- Mix 1 drop of Primer A (Batch No. 0600004826) and & spoon of powder with 1 & s, rinse and gently air-dry \\
1 drop of Primer B (Batch No. 0600004832) from All Bond 2, & drop of liquid & - Mix paste A and paste B \\
apply the mixture to dentin and air-dry for 5 s & - Apply the cement & - Apply the cement onto the \\
- Apply Pre-Bond Resin to dentin & onto the post and insert & post and insert it into the \\
- Mix base and catalyst for 10 s & it into the post space & $\begin{array}{c}\text { post space } \\
\text { - Apply the cement onto the post and insert it into the post space }\end{array}$ \\
- Light-cure for 40 s & &
\end{tabular}


push-out bond strength $(\mathrm{p}<0.05)$, although these factors did not interact with each other ( $\mathrm{p}>0.05$ ).

Post-hoc comparisons showed that the three cements differed significantly from each other. $\mathrm{CB}$ showed the highest bond strength $(\mathrm{p}<0.05)$, followed by $\mathrm{KC}$ and $\mathrm{FC}$ after all water storage times.

All cements exhibited significantly higher bond strength $(p<0.05)$ in T7 and T90 than in the control group.

\section{DISCUSSION}

The results of this study require rejection of the null hypothesis that the cement type and the water storage time do not affect the push-out bond strength of the luted glass fiber posts. The differences among the several cements available are influenced by their idiosyncratic compositions. In the present study, CB had the highest mean push-out bond strength values, followed by $\mathrm{KC}$ and $\mathrm{FC}$, regardless of the water storage time. In general, the three cements exhibited an increase in the bond strength of fiber posts after 7 and 90 days, and a decrease after 180 days occurred for CB or 90 days for FC. KC showed the maximum bond strength after 7 days, stabilizing afterwards. This behavior was probably caused by the water sorption and subsequent hygroscopic expansion of the cements and/or by continuation of its setting reaction. Such a phenomenon might have increased the frictional resistance of the cements against the root canal walls and, subsequently, improved fiber post retention.

The remarkably superior performance of the adhesion in the root canal when using $\mathrm{CB}$ may be explained by the unique characteristics of this material. The dentin conditioner that is part of the CB system, which is composed of $32 \%$ phosphoric acid/ benzalkonium chloride solution, has the ability to remove the smear layer, etch and demineralize dentin. This allows monomers with small molecular size to penetrate the opened tubules and the space between the collagen fibrils in the demineralized dentin, creating resin tags and hybrid layer. These structures provide an effective micromechanical retention mechanism for this resin-based cement.

Push-out bond strengths recorded for $\mathrm{KC}$ were intermediate between $\mathrm{CB}$ and $\mathrm{FC}$ throughout the present study. GICs bonding mechanism relies on the micromechanical retention of the polymer within the dentin substrate conditioned by the polycarboxylic acid, and also on the ionic interaction between the cement and dentin (11). Although this cement did not show the highest push-out bond strength values, such a secondary chemical interaction may have stabilized the bond in the adhesive interface and generated a more uniform strength for the GIC in this study (12).

FC had the lowest push-out bond strength throughout the study, despite the presence of the resinous polymeric matrix. The adhesion mechanism of RMGICs relies on the technology of GIC modified by the addition of hydrophilic resinous monomers (HEMA [2-hydroxyethyl methacrylate] and dimethacrylate). This cement presents a dual setting reaction characterized by an initial monomer polymerization followed by the classic acid-base reaction (13). However, this approach was less effective than that of the other cements evaluated in this study.

The process of water uptake is generally time dependent and material dependent. Thus, the amount of water absorbed into the cement layer is expected to increase with time until the material is saturated and hydrolytically stable (14). Water storage improved the bond strength of CB after 7 and 90 days in relation to the control group because hydrophilic monomers likely absorbed water from the underlying dentin and undergone hygroscopic expansion. Nevertheless, the resinous matrix may have undergone a process of plasticization and softening over time, resulting in a reduction in strength after 180 days.

Immediate strength in $\mathrm{KC}$ was significantly higher after 7 and 90 days of water storage in comparison to the control group, decreasing in T180. In spite of

Table 3. Mean values and standard deviation (MPa) of the push-out bond strength for the different cements and water storage times.

\begin{tabular}{lccccc}
\hline \multirow{2}{*}{ Cement type } & \multicolumn{5}{c}{ Water storage time } \\
\cline { 2 - 6 } & Control & T1 & T7 & T90 & T180 \\
\hline C\&B Cement & $7.66 \pm 2.67 \mathrm{Aa}$ & $9.45 \pm 3.08 \mathrm{Aab}$ & $11.47 \pm 1.54 \mathrm{Ab}$ & $14.56 \pm 2.55 \mathrm{Ab}$ & $9.79 \pm 2.68 \mathrm{Aab}$ \\
KetacCem & $7.16 \pm 4.29 \mathrm{Ba}$ & $7.34 \pm 2.47 \mathrm{Bab}$ & $9.19 \pm 3.81 \mathrm{Bb}$ & $9.79 \pm 2.02 \mathrm{Bb}$ & $9.34 \pm 3.19 \mathrm{Bab}$ \\
GC FujiCEM & $2.80 \pm 1.04 \mathrm{Ca}$ & $7.02 \pm 1.50 \mathrm{Cab}$ & $7.21 \pm 1.32 \mathrm{Cb}$ & $5.48 \pm 2.64 \mathrm{Cb}$ & $5.21 \pm 2.34 \mathrm{Cab}$ \\
\hline
\end{tabular}

Different uppercase letters in the same column and lowercase letters in the same row indicate statistically significant difference ( $<<0.05$ ). 
that, this cement showed a stable bonding performance throughout the water storage time of 180 days. In addition the hygroscopic expansion, this may be explained by the late maturation phenomenon of the GICs (15). Initially, the acid-base reaction releases metal ions from fluoraluminum-silicate fillers and creates a silica hydrogel layer on the surface of the glass particles. Then, a crosslinking between these ions and the polycarboxilic acid creates a poly-salt matrix (16). The osmotic gradient formed in such matrix attracts residual water from the underlying dentin, which initiates the additional acid-base reaction and creates hollow spherical structures similar to "egg shells" (12). These structures represent a silica-rich phase that plays an important role in the late maturation of GICs, and have likely contributed to the more uniform results of strengths for the GIC in this study.

Initially, FC showed an extremely low push-out bond strength, which increased considerably after the first day and significantly after 7 days. RMGICs absorb large amounts of water in the first week and show variable volumetric expansion between 3.4 and 11.3\% (17). These cements attract water due to the presence of hydrophilic resin monomers in the cement layer. However, since the bond strength of FC decreased after 90 days of water storage, it is likely that the presence of water on the layer of cement decreased the electrostatic interactions among hydroxyl groups in the resin monomers (18).

This study has a few limitations. It is not possible to ensure the full efficiency of coronal seal in avoiding water sorption from the external environment. Thus, it was not possible to determine with certainty whether the observed phenomenon was caused by the water source from the external environment or by the residual water within intraradicular dentin. As suggested by Cury et al. (7), a new research protocol should be established in the future by long-term aging the experimental specimens in mineral oil. This way, it will be possible to determine if the same behavior of these cements would be observed using only residual water present inside the dentin tubules. Furthermore, it is not possible to predict whether the push-out bond strength variation found in vitro would cause any clinically significant changes since it is unclear whether the amount of moisture exposure at the cement-dentin interface found in this study is similar to that of the clinical situation.

This study assessed the differences in the pushout bond strength only among the cements exposed to either no or different water storage times, without taking into account the coronal, middle and apical root canal regions with respect to dentinal tubule size. Onay et al. (19) reported a significant difference in push-out bond strength among these three root regions. This difference in dentinal tubule size may have affected the amount of moisture available for the suggested advantage of hygroscopic expansion of the cements. Although the present study used five to six slices of each root specimen, the regional differences was not considered.

Recently, new self-adhesive resin cements have been proposed for glass fiber post luting. It would also be interesting to conduct more studies with these cements to allow the assessment of their long-term performance under similar conditions of water storage (20).

In conclusion, $\mathrm{CB}$ showed the best bonding performance throughout the 180-day water storage period, clearly indicating an advantage in glass fiber post cementation over the other materials. All cements exhibited a tendency to increase the bond strength after 7 and 90 days of water storage, decreasing thereafter.

\section{RESUMO}

Este estudo investigou os efeitos do tipo de cimento e do tempo de armazenamento em água na resistência adesiva ao cisalhamento de pinos de fibra. Pinos de fibra de vidro (Fibrekor, JenericPentron) foram cimentados aos condutos radiculares usando o cimento resinoso autopolimerizável (C\&B Cement [CB]), o cimento de ionômero de vidro (Ketac Cem [KC]) ou o cimento de ionômero de vidro modificado por resina (GC FujiCEM [FC]) de acordo com as instruções dos fabricantes. Para cada cimento, os espécimes foram expostos a um dos seguintes tempos de armazenamento em água (n=5): 1 dia (T1), 7 dias (T7), 90 dias (T90) e 180 dias (T180). Os testes de resistência adesiva ao cisalhamento foram realizados após os períodos de armazenamento. Os espécimes controles não foram expostos ao armazenamento em água, mas submetidos ao teste de resistência adesiva ao cisalhamento 10 min após a cimentação do pino. Os dados (MPa) foram analisados usando Kruskal-Wallis e teste de Dunn $(\alpha=0,05)$. O tipo de cimento e o tempo de armazenamento em água afetaram significantemente a resistência adesiva ao cisalhamento $(p<0,05)$. $\mathrm{CB}$ apresentou valores de retenção significantemente superiores a $\mathrm{KC}$ e FC, independentemente do tempo de armazenamento em água. Esse, por sua vez, aumentou significantemente a resistência adesiva ao cisalhamento em T7 e T90, independentemente do tipo de cimento $(p<0,05)$. Os resultados indicaram que os pinos de fibra cimentados aos condutos radiculares com o cimento resinoso autopolimerizável apresentou a melhor performance adesiva durante todo o período de armazenamento em água de 180 dias. Todos os cimentos apresentaram uma tendência a aumentar a resistência adesiva ao cisalhamento após 7 e 90 dias de armazenamento em água, diminuindo posteriormente.

\section{REFERENCES}

1. Zogheib LV, Pereira JR, do Valle AL, de Oliveira JA, Pegoraro 
LF. Fracture resistance of weakened roots restored with composite resin and glass fiber post. Braz Dent J 2008;19:329-333.

2. Zicari F, Van Meerbeek B, Debels E, Lesaffre E, Naert I. An up to 3-year controlled clinical trial comparing the outcome of glass fiber posts and composite cores with gold alloy-based posts and cores for the restoration of endodontically treated teeth. Int $\mathrm{J}$ Prosthodont 2011;24:363-372.

3. Bitter K, Paris S, Pfuertner C, Neumann K, Kielbassa AM. Morphological and bond strength evaluation of different resin cements to root dentin. Eur J Oral Sci 2009;117:326-333.

4. Bonfante EA, Pegoraro LF, de Goes MF, Carvalho RM. SEM observation of the bond integrity of fiber-reinforced composite posts cemented into root canals. Dent Mater 2008;24:483-491.

5. Mannocci F, Innocenti M, Ferrari M, Watson TF. Confocal and scanning electron microscopic study of teeth restored with fiber posts, metal posts, and composite resins. J Endod 1999;25:789794.

6. Bouillaguet S, Troesch S, Wataha JC, Krejci I, Meyer JM, Pashley DH. Microtensile bond strength between adhesive cements and root canal dentin. Dent Mater 2003;19:199-205.

7. Cury AH, Goracci C, de Lima Navarro MF, Carvalho RM, Sadek FT, Tay FR, et al.. Effect of hygroscopic expansion on the push-out resistance of glass ionomer-based cements used for the luting of glass fiber posts. J Endod 2006;32:537-540

8. Dauvillier BS, Feilzer AJ, De Gee AJ, Davidson CL. Visco-elastic parameters of dental restorative materials during setting. J Dent Res 2000;79:818-823.

9. Yiu CK, Tay FR, King NM, Pashley DH, Carvalho RM, Carrilho MR. Interaction of resin-modified glass-ionomer cements with moist dentine. J Dent 2004;32:521-530.

10. Chersoni S, Acquaviva GL, Prati C, Ferrari M, Grandini S, Pashley $\mathrm{DH}$, et al.. In vivo fluid movement through dentin adhesives in endodontically treated teeth. J Dent Res 2005;84:223-227.
11. Lin A, McIntyre NS, Davidson RD. Studies on the adhesion of glass-ionomer cements to dentin. J Dent Res 1992;71:1836-1841.

12. Yiu CK, Tay FR, King NM, Pashley DH, Sidhu SK, Neo JC, et al.. Interaction of glass-ionomer cements with moist dentin. J Dent Res 2004;83:283-289.

13. Berzins DW, Abey S, Costache MC, Wilkie CA, Roberts HW. Resin-modified glass-ionomer setting reaction competition. J Dent Res 2010;89:82-86.

14. Chai J, Takahashi Y, Hisama K, Shimizu H. Water sorption and dimensional stability of three glass fiber-reinforced composites. Int J Prosthodont 2004;17:195-199.

15. Cattani-Lorente MA, Godin C, Meyer JM. Mechanical behavior of glass ionomer cements affected by long-term storage in water. Dent Mater 1994;10:37-44.

16. Pires RA, Nunes TG, Abrahams I, Hawkes GE. The role of aluminium and silicon in the setting chemistry of glass ionomer cements. J Mater Sci Mater Med 2008;19:1687-1692.

17. Huang C, Kei LH, Wei SH, Cheung GS, Tay FR, Pashley DH. The influence of hygroscopic expansion of resin-based restorative materials on artificial gap reduction. J Adhes Dent 2002;4:61-71.

18. Cattani-Lorente MA, Dupuis V, Payan J, Moya F, Meyer JM. Effect of water on the physical properties of resin-modified glass ionomer cements. Dent Mater 1999;15:71-78.

19. Onay EO, Korkmaz Y, Kiremitci A. Effect of adhesive system type and root region on the push-out bond strength of glass-fibre posts to radicular dentine. Int Endod J 2010;43:259-268.

20. Zaitter S, Sousa-Neto MD, Roperto RC, Silva-Sousa YT, ElMowafy O. Microtensile bond strength of glass fiber posts cemented with self-adhesive and self-etching resin cements. J Adhes Dent 2011;13:55-59. 